\title{
A Comparative Study of Observed and Predicted Austenite Micro- structures during Hot Rolling of a Medium Carbon Steel
}

\section{J. J. CRUZ-RIVERA, J. G. CABAÑAS-MORENO and Minoru UMEMOTO"1)}

Instituto Politécnico Nacional, ESIQIE, Apdo. Postal 75-373, México, D. F., 07300, Mexico.

1) Toyohashi University of Technology, Department of Production Systems Engineering, Tempaku-cho, Toyohashi, Aichi-ken, 441, Japan.

(Received on June 19, 1995; accepted in final form on November 29, 1995)

\begin{abstract}
Two-step deformation sequences, applied by laboratory rolling to a medium carbon steel, were used to assess the applicability of the most important models of microstructural evolution to describe the actual behavior of the austenite in this material. The model developed by the IRSID group gave the best overall agreement with the metallographic observations, mainly due to a better prediction of the rates of grain growth in the temperature range of 1173 to $1473 \mathrm{~K}$, as compared to the models proposed by the researchers at Sheffield University and Nippon Steel Corp., which predictions resulted grossly inaccurate at the higher temperatures. Nevertheless, all three models contain the essential features to lead to reasonable values of the austenite grain size, especially as the number of deformation steps increases concurrently with a progressive decrease in the temperatures of deformation.
\end{abstract}

KEY WORDS: microstructure prediction; recrystallization; grain growth; hot rolling; carbon steels; austenite grain size.

\section{Introduction}

Starting with the pioneering work of Sellars, ${ }^{1)}$ a considerable amount of effort has been devoted to the development of models to predict the way in which the microstructure of austenite in steels evolves during thermomechanical processing. ${ }^{1-8)}$ As regards the microstructural evolution in carbon steels, current mathematical models include all major metallurgical phenomena affecting the grain size of hot-worked austenite (i.e., recrystallization, recovery, grain growth), as well as those concerning the transformation of austenite into stable or metastable, low temperature phases. ${ }^{2)}$ The accuracy of the models' predictions is usually stated to be quite good, but very rarely the models have been applied to the same set of experimental conditions and materials in order to make a direct comparison of their predictive capabilities. In addition, it is frequently the case that the evaluation of a whole sequence of microstructural evolution-involving the events occurring during both hot-working and subsequent cooling of austenite-is based on one single indirect measurement, for example, the final ferrite grain size. In most cases, of course, in-plant experiments are restricted in the way sampling of specimens at different stages of the thermomechanical treatment can be done. But the confidence in the predictions of the models can be increased if it is proved that the agreement with experimental results is based on an adequate description of all the metallurgical phenomena involved, rather than on a fortunate choice of equations.

Sellars ${ }^{10}$ ) has indicated that there are indeed some differences in the quantitative predictions of the main models of microstructural evolution when applied to the same set of conditions. Since the amount of experimental work required in the development of such models is quite large, it might be useful to investigate in detail under which circumstances each of the main models performs better, as well as to know how large differences one could expect among the predictions of the different models. In the present work we provide an evaluation of three models of microstructural evolution of austenite by comparing their predictions with actual results obtained in laboratory hot-rolling experiments. Since this study was motivated by a specific industrial application, the material used (a medium carbon steel) and its initial condition (continuous cast billet) were features not commonly encountered in previous works, and it was also intended to clarify to what extent these features could influence the microstructural evolution of austenite, as described by the models' equations. In addition to this, the applied deformations were usually restricted to a value of 0.2 true strain, while the deformation and holding temperatures were mostly in the range at which the continuously cast material would be reheated in preparation for subsequent rolling. The static recrystallization bahavior of the same material has been described in a recent report. ${ }^{11)}$ 
(a)
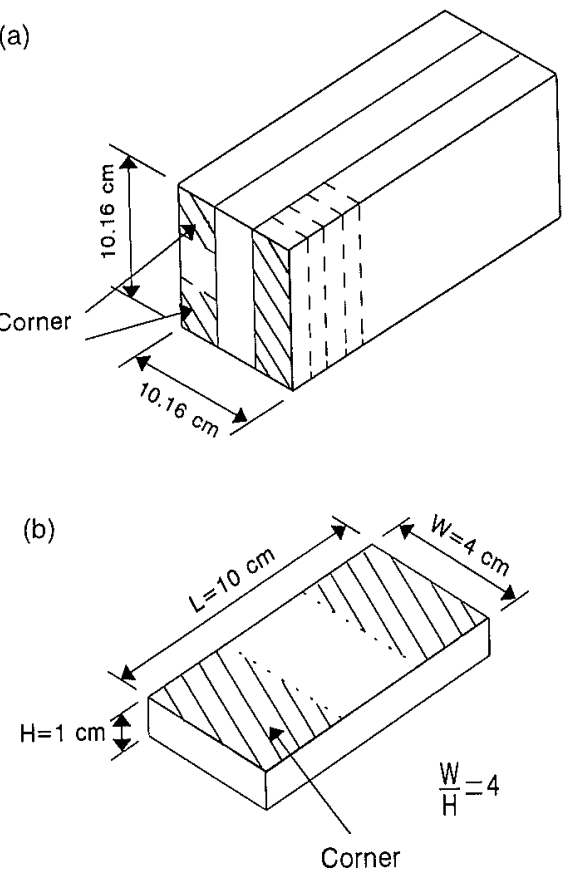

Fig. 1. (a) Specimen taken from the continuous cast steel billet, (b) Shape and dimensions of the specimens for hot rolling experiments.

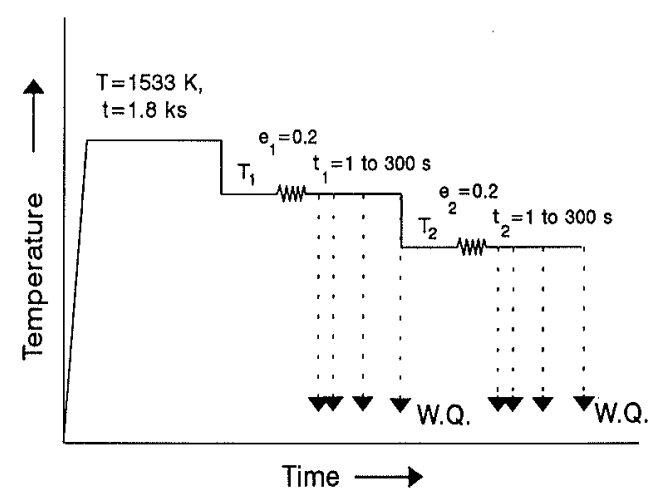

Fig. 2. Deformation sequences by hot rolling.

Table 1. Conditions of deformation in hot rolling experiments.

\begin{tabular}{ccccc}
\hline Schedule & $T_{1}(\mathrm{~K})$ & $e_{1}$ & $T_{2}(\mathrm{~K})$ & $e_{2}$ \\
\hline A-B & 1473 & 0.2 & 1423 & 0.2 \\
A-C & 1473 & 0.2 & 1373 & 0.2 \\
A-D & 1473 & 0.2 & 1273 & 0.2 \\
A-E & 1473 & 0.2 & 1173 & 0.2 \\
C-D & 1373 & 0.2 & 1273 & 0.2 \\
D-E & 1273 & 0.2 & 1173 & 0.2 \\
\hline
\end{tabular}

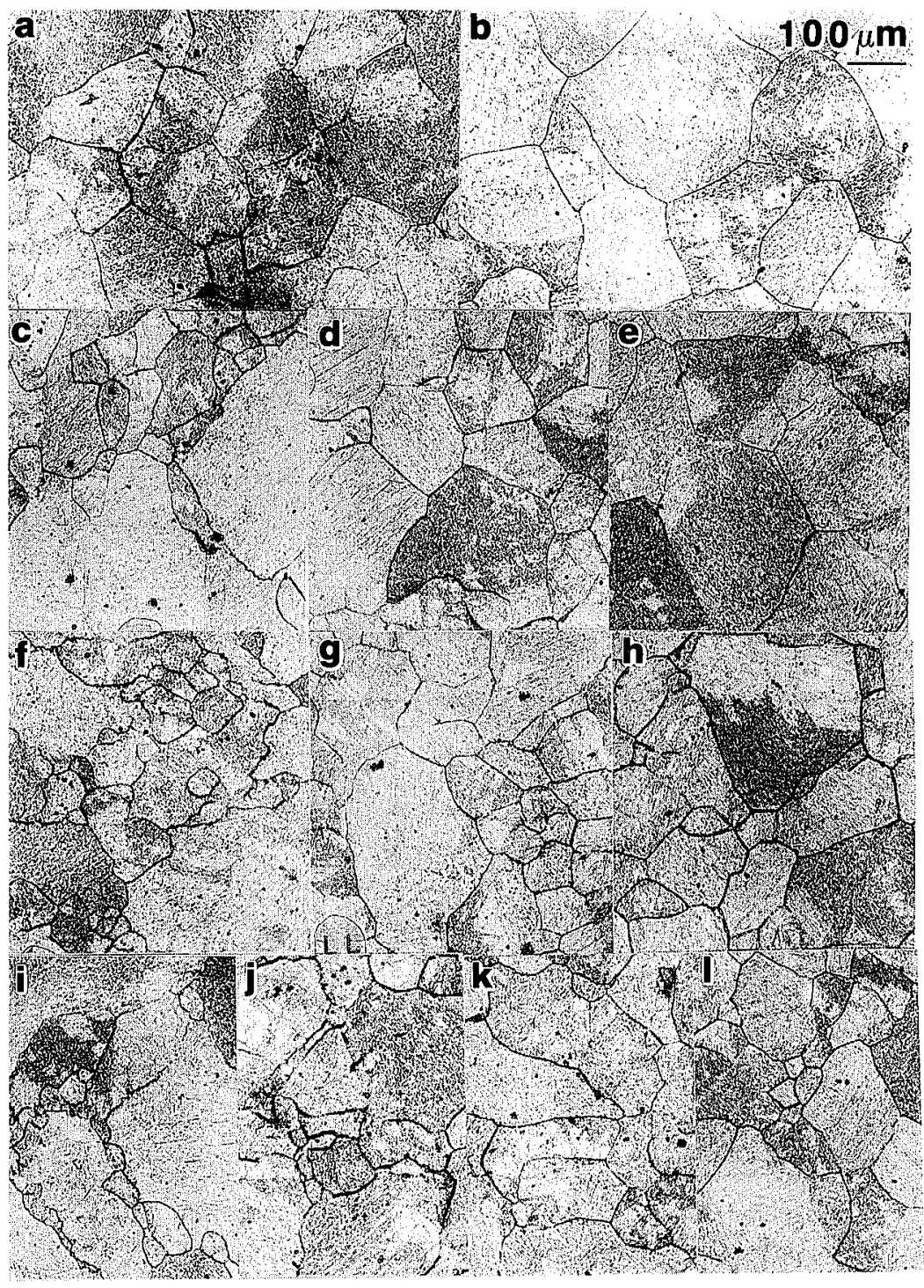

Fig. 3.

Microstructures observed in deformed specimens: (a-b) 1st step of sequence A-B $\left(t_{h}=1\right.$ and $\left.220 \mathrm{~s}\right)$; (c-e) 1st step of sequence $\mathrm{C}-\mathrm{D}\left(t_{h}=1,60\right.$ and $\left.300 \mathrm{~s}\right) ;(\mathrm{f}-\mathrm{h})$ 1st step of sequence D-E $\left(t_{h}=1,60\right.$ and $\left.300 \mathrm{~s}\right)$; (i-l) 2nd step of sequence A-E ( $t_{h}=1,60,120$ and $\left.300 \mathrm{~s}\right)$. 


\section{Experimental Procedure}

The chemical composition of the steel used in this study was (wt \%): $0.44 \mathrm{C}, 0.90 \mathrm{Mn}, 0.28 \mathrm{Si}, 0.06 \mathrm{Cr}, 0.028 \mathrm{P}$, $0.003 \mathrm{~S}, 0.003 \mathrm{Al}$. It was obtained as a continuously cast billet of $10.16 \times 10.16 \mathrm{~cm}^{2}$ cross section.

Specimens for hot rolling experiments were cut from the billet in the manner depicted in Fig. 1(a). Their shape and dimensions after machining are shown in Fig. 1(b). The thickness of the specimens was varied according to the needs of the experiments, and the width-to-thickness ratio was kept at $4: 1$ to maintain mainly plane-strain conditions during deformation. The bore in the specimens shown in Fig. 1(b) was used to hold a fine-wired alumel-chromel thermocouple to monitor the temperature of each specimen at all times during the deformation sequence.

Hot rolling was carried out in a two-high laboratory rolling mill, under actual strain rates in the range from 8 to $9 \mathrm{~s}^{-1}$. Each of the experiments included two deformation steps in the manner depicted in Fig. 2. The amount of deformation in each step was 0.2 (true strain). The initial austenitization treatment was given at $1533 \mathrm{~K}$, resulting in an average austenite grain size of $270 \mu \mathrm{m}$. After each deformation step the specimens were transferred to large resistance furnaces held at predetermined temperatures, at which recrystallization and grain growth were allowed to occur under approximately isothermal conditions. All furnace operations were carried out without any protective atmosphere. Table 1 gives the details of the temperatures used for deformation and holding operations, as well as the range of holding time periods applied in the different deformation sequences. Because of the deformation conditions indicated in Table 1, no dynamic recrystallization of austenite would be expected to develop during the present experiments. ${ }^{11)}$ This was confirmed by the models' calculations which are described in a later section.

As indicated in Fig. 2, at different stages during a given deformation sequence specimens were rapidly $(<1 \mathrm{~s})$ removed from the furnace and quenched in water. The parts of the specimens corresponding to the corners of the billet shown in Fig. 1(a) were chosen to examine the state of the austenitic microstructure at the different stages. Previous studies ${ }^{11,12)}$ had shown that only small differences occurred in the microstructural evolution of specimens taken from other locations in the billet. Sections longitudinal and transverse to the billet length were used in the microstructural examination, and actual observations were restricted to the central regions on these sections, far away from surface areas which had undergone oxidation and/or decarburization.

Specimens were prepared by standard procedures for
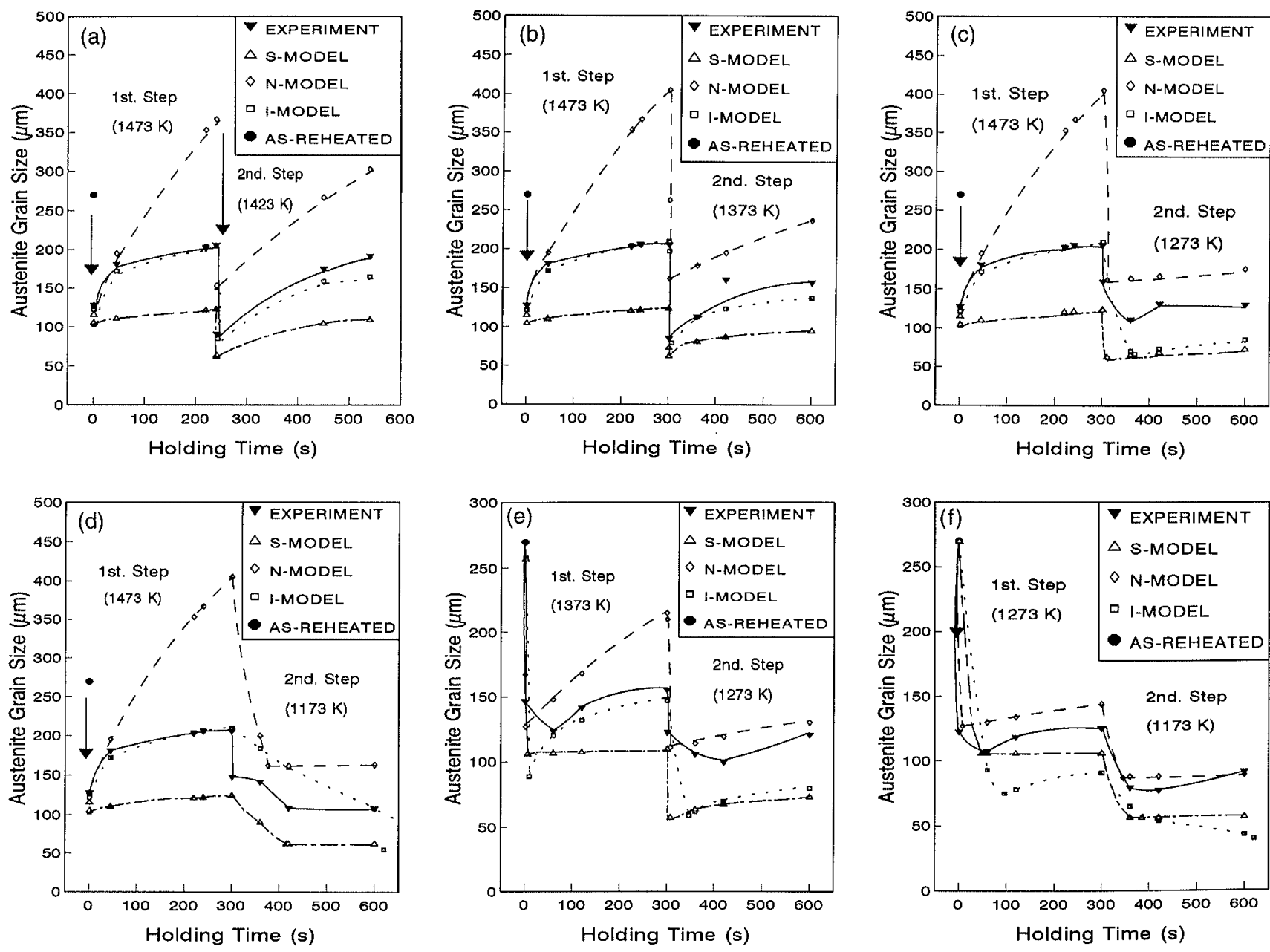

Fig. 4. (a) to (f) Measured austenite grain sizes at different stages of deformation sequences A-B, A-C, A-D, A-E, C-D and D-E, respectively. 
metallographic observations. Etching was accomplished by using an aqueous solution of picric acid and a commercially available surfactant agent. By varying as needed the temperature and duration of etching, prior austenite grain boundaries could be clearly revealed in all specimens. Some examples of the microstructures observed are given by the micrographs shown in Fig. 3. Austenite grain sizes were determined as mean linear intercept lengths, following ASTM standard E-112-77.

\section{Results}

\subsection{Experimental Results}

The measured austenite grain sizes at different stages of the deformation sequences indicated in Table 1 are presented in Fig. 4 and Table 2. These results show that the reheated, as-cast material subjected to a deformation of 0.2 at temperatures in the ranges $1273-1473 \mathrm{~K}$, in all cases underwent very fast recrystallization within the time interval $(<1 \mathrm{~s})$ spent in transferring the specimens from the rolling mill to the water quench. Completely recrystallized microstructures occurred in those specimens deformed at $1473 \mathrm{~K}$, as indicated by the tendency to grain growth in specimens transferred to a second furnace immediately after deformation (Figs. 4(a) to 4(d)) and illustrated by the micrographs in Figs. 3(a) and 3(b). Notice in Figs. 3(a) and 3(b) that the traces of the austenite grain boundaries are predominantly straight, and not serrated, the latter feature usually associated with grains resulting directly from the occurrence of dynamic recrystallization. On the other hand, those specimens reheated in the as-cast condition and deformed at 1273 and $1373 \mathrm{~K}$ (Figs. 4(e), 4(f)) show a slight grain refinement on holding at high temperature during the first $\sim 75 \mathrm{sec}$ after deformation; this is taken as evidence of continuing recrystallization during the holding period, and it is confirmed by the disappearance of the large austenite grains present right after hotrolling - compare, for example, Figs. 3(c) and 3(f) with Figs. $3(\mathrm{~d})$ and $3(\mathrm{~g})$, respectively. Notice again that the straightness of most grain boundary traces indicates that the above microstructures have not been produced by dynamic recrystallization. After holding times longer than abut $100 \mathrm{~s}$, the tendency to overall grain growth is also observed at the temperatures of 1273 and $1373 \mathrm{~K}$ (see Figs. 3(e), 3(h) and 4(e), 4(f)). After a holding period of about $250 \mathrm{~s}$ after the first deformation step, the rate of grain growth seemed to become almost null, irrespective of the holding temperature in the range $1273-1473 \mathrm{~K}$ (Figs. 4(a) to 4(f)).

As expected, the austenite grain sizes observed at the stages of apparently no further grain growth are larger as the holding temperature increases. However, the apparent recrystallized grain sizes (taken here as the minimum experimental values shown in Figs. 4(a) to 4(f) are practically independent of temperature and with values in the range of $107-127 \mu \mathrm{m}$.

The second deformation step of the sequences described in Table 1 was applied to materials that had fully recrystallized structures (e.g., Figs. 3(b), 3(e), 3(h)) but, because of different growth rates, also different grain
Table 2. Measured average grain sizes of austenite.

\begin{tabular}{|c|c|c|c|c|c|}
\hline \multicolumn{4}{|c|}{ Experimental conditions } & \multirow{2}{*}{$d_{\text {meas }}(\mu \mathrm{m})$} & \multirow{2}{*}{ Schedule/Step } \\
\hline$T(\mathrm{~K})$ & $d_{i}(\mu \mathrm{m})$ & Strain & $t_{h}(\mathrm{~s})$ & & \\
\hline 1473 & 270 & 0.2 & $\begin{array}{r}\sim 1 \\
45 \\
220 \\
240 \\
300\end{array}$ & $\begin{array}{l}127 \pm 8 \\
180 \pm 13 \\
202 \pm 8 \\
205 \pm 12 \\
205 \pm 8\end{array}$ & $A-B$ to $A-E / 1 s t$ \\
\hline 1423 & 205 & 0.2 & $\begin{array}{l}\sim 1 \\
210 \\
300\end{array}$ & $\begin{array}{r}90 \pm 6 \\
174 \pm 14 \\
191 \pm 19\end{array}$ & $\mathrm{~A}-\mathrm{B} / 2 \mathrm{nd}$ \\
\hline 1373 & 270 & 0.2 & $\begin{array}{r}\sim 1 \\
60 \\
120 \\
300\end{array}$ & $\begin{array}{l}146 \pm 21 \\
123 \pm 11 \\
141 \pm 6 \\
155 \pm 6\end{array}$ & $\mathrm{C}-\mathrm{D} / \mathrm{lst}$ \\
\hline 1373 & 205 & 0.2 & $\begin{array}{r}\sim 1 \\
60 \\
120 \\
300\end{array}$ & $\begin{array}{r}85 \pm 8 \\
113 \pm 5 \\
160 \pm 10 \\
157 \pm 5\end{array}$ & $\mathrm{~A}-\mathrm{C} / 2 \mathrm{nd}$ \\
\hline 1273 & 270 & 0.2 & $\begin{array}{r}\sim 1 \\
60 \\
120 \\
300\end{array}$ & $\begin{array}{l}122 \pm 21 \\
107 \pm 5 \\
118 \pm 6 \\
125 \pm 5\end{array}$ & D-E/1st \\
\hline 1273 & 205 & 0.2 & $\begin{array}{r}\sim 1 \\
60 \\
120 \\
300\end{array}$ & $\begin{array}{l}159 \pm 10 \\
111 \pm 3 \\
131 \pm 7 \\
130 \pm 12\end{array}$ & $\mathrm{~A}-\mathrm{D} / 2 \mathrm{nd}$ \\
\hline 1273 & 155 & 0.2 & $\begin{array}{r}\sim 1 \\
60 \\
120 \\
300\end{array}$ & $\begin{array}{r}122 \pm 12 \\
105 \pm 4 \\
99 \pm 4 \\
120 \pm 8\end{array}$ & $\mathrm{C}-\mathrm{D} / 2 \mathrm{nd}$ \\
\hline 1173 & 205 & 0.2 & $\begin{array}{r}\sim 1 \\
60 \\
120 \\
300\end{array}$ & $\begin{array}{l}147 \pm 20 \\
141 \pm 17 \\
108 \pm 3 \\
107 \pm 3\end{array}$ & $\mathrm{~A}-\mathrm{E} / 2 \mathrm{nd}$ \\
\hline 1173 & 125 & 0.2 & $\begin{array}{l}\sim 1 \\
100 \\
160 \\
300\end{array}$ & $\begin{array}{r}125 \pm 16 \\
79 \pm 5 \\
77 \pm 6 \\
91 \pm 5\end{array}$ & $D-E / 2 n d$ \\
\hline
\end{tabular}

$d_{i}=$ grain size before corresponding (1st or 2 nd) deformation step $d_{\text {meas }}=$ measured grain size after deformation and holding period $t_{h}=$ holding time at temperature after deformation

sizes; from about $125 \mu \mathrm{m}$ in specimens undergoing schedule D-E, up to about $205 \mu \mathrm{m}$ in specimens subjected to schedules $\mathrm{A}-\mathrm{B}$ to $\mathrm{A}-\mathrm{D}$, as well as an intermediate value of about $155 \mu \mathrm{m}$ in schedule C-D (Table 2). After the second deformation step, complete recrystallization occurred again within the shortest time available before quenching $(<1 \mathrm{~s})$ in specimens of schedules $\mathrm{A}-\mathrm{B}$ and $\mathrm{A}-\mathrm{C}$, i.e., those having a grain size of about $205 \mu \mathrm{m}$ before being deformed at 1423 and $1373 \mathrm{~K}$, respectively (Figs. 4(a), 4(b)). In turn, the second deformation step at temperatures of 1273 and $1173 \mathrm{~K}$ in specimens with the same grain size of $205 \mu \mathrm{m}$ produced recrystallization at a slower pace (Figs. 4(c), 4(d)); even slower rates of recrystallization are observed (e.g., Figs. 
3(i) to 3(1)) after the second deformation step for smaller initial grain sizes at the latter temperatures (Figs. 4(e), 4(f)). Nevertheless, all deformation schedules seem to lead to complete recrystallization with holding times of $300 \mathrm{~s}$ or less after the second deformation step.

Specimens with a grain size of about $205 \mu \mathrm{m}$ just before the second deformation step attained a recrystallized grain size in the range of 85 to $111 \mu \mathrm{m}$, for temperatures between 1173 and $1423 \mathrm{~K}$ (Figs. 4(a) to 4(d)). A grain size of about a $100 \mu \mathrm{m}$ is indicated in schedule C-D (Fig. 4(e)), in which the corresponding grain size before the second deformation was $\sim 150 \mu \mathrm{m}$. In contrast to the above recrystallized grain sizes, specimens in schedule D-E, deformed at $1173 \mathrm{~K}$ with a grain size of $\sim 100 \mu \mathrm{m}$, possess a somewhat smaller recrystallized grain size $(\sim 77 \mu \mathrm{m})$ after the second deformation step (Fig. 4(f)).

Final grain sizes after grain growth in the last step of all schedules indicated in Table 1 seem to depend again primarily on the holding temperature (Table 2). These grain sizes go from about $190 \mu \mathrm{m}$ at a holding tempeature of $1423 \mathrm{~K}$ (Fig. 4(a)), down to about 90-110 $\mu \mathrm{m}$ at a holding temperature of $1173 \mathrm{~K}$ (Figs. 4(d), 4(f)).

The results obtained in some of the hot deformation experiments described in Tables 1 and 2 can be used to observe, at a constant strain (0.2) and temperature $(1173,1273$ or $1373 \mathrm{~K}$ ), the effect of gran size before deformation on the values of the grain size after recrystallization and after subsequent grain growth. Thus, at $1373 \mathrm{~K}$, the change in initial grain size from 270 to $205 \mu \mathrm{m}$ apparently causes a visible change in the recrystallized grain sizes, from $\sim 123$ to $\sim 85 \mu$ m respectively, but it shows no effect on the grain sizes after growth $(155-157 \mu \mathrm{m})$. At $1273 \mathrm{~K}$, the same change in initial grain size apparently does not produce different recrystallized grain sizes $(107-111 \mu \mathrm{m})$, although a further decrease of the former down to $155 \mu \mathrm{m}$ induces a slightly smaller recrystallized grain size of $\sim 100 \mu \mathrm{m}$; in turn, the grain sizes after grain growth are all in range 120 to $130 \mu \mathrm{m}$. Finally, at $1173 \mathrm{~K}$, decreasing the initial grain size from 205 to $125 \mu \mathrm{m}$ gives rise to a change of the recrystallized grain size from $\sim 107$ to $\sim 77 \mu \mathrm{m}$; in addition, the grain sizes after growth apparently change too, $\sim 107$ to $\sim 91 \mu \mathrm{m}$.

\subsection{Models' Calculations}

The models of microstructural evolution which have been applied to the present work are those developed (i) at the University of Sheffield by C.M. Sellars and coworkers, ${ }^{1,2)}$ (ii) at IRSID (France) by P. Choquet and coworkers, ${ }^{3,4)}$ and (iii) at Nippon Steel Corp. by H. Yada and coworkers. ${ }^{5,6,13,14)}$ Henceforth, these models will be referred to as the S-, I-, and N-models respectively. For economy of space, all the equations included in the above models are not reproduced here, but those most relevant to the discussion of the present work are listed in Table 3. The calculation procedures in these models are straightforward, as long as only deformation of fully recrystallized structures is involved, which is the case in the experiments described here. For the purposes of calculation, by fully recrystallized
Table 3. Relevant equations for the calculation of recrystallized grain sizes and grain growth.

Recrystallized grain size

$$
\begin{array}{ll}
\text { S-Model } & d_{\mathrm{rex}}(\mu \mathrm{m})=0.5 d_{i}^{0.67} e^{-1} \\
\text { I-Model } & d_{\mathrm{rex}}(\mu \mathrm{m})=45 d_{i}^{0.374} e^{-0.6} \dot{e}^{-0.1} \exp (-25000 / R T) \\
\text { N-Model } & d_{\mathrm{rex}}(\mu \mathrm{m})=5 S_{v}^{-0.6} e^{-0.6}
\end{array}
$$

\begin{tabular}{|c|c|}
\hline & Grain growth \\
\hline \multirow[t]{4}{*}{ S-Model } & $d^{10}\left(\mu \mathrm{m}^{10}\right)=d_{\mathrm{rcx}}^{10}+3.87 \times 10^{32} t^{\prime} \exp (-400000 / R T)$ \\
\hline & $T \geq 1273 \mathrm{~K}$ \\
\hline & $d^{10}\left(\mu \mathrm{m}^{10}\right)=d_{\mathrm{rex}}^{10}+5.02 \times 10^{53} t^{\prime} \exp (-914000 / R T)$ \\
\hline & $T \leq 1273 \mathrm{~K}$ \\
\hline I-Model & $d(\mu \mathrm{m})=d_{\mathrm{rex}}+\left[1+0.195 \ln \left(t^{\prime \prime} / t_{0.99}\right)\right]$ \\
\hline N-Model & $d^{2}\left(\mu \mathrm{m}^{2}\right)=d_{\mathrm{rcx}}^{2}+1.44 \times 10^{12} t^{\prime} \exp (-226700 / R T)$ \\
\hline
\end{tabular}

$d_{\text {rex }}$, recrystallized grain size $(\mu \mathrm{m}) ; d_{i}$, initial grain size $(\mu \mathrm{m}) ; e$, applied true strain rate $\left(\mathrm{s}^{-1}\right) ; R=8.31 \mathrm{~J} \mathrm{~mol}^{-1} \mathrm{~K}^{-1} ; T$, deformation or holding temperature $(\mathrm{K}) ; S_{1}$, strain-modified grain surface area $\left(\mu \mathrm{m}^{-1}\right.$-see Refs. 13), 14); $d$, grain size $(\mu \mathrm{m})$ at time $t^{\prime}$ or $t^{\prime \prime} ; t^{\prime}$, time elapsed after $95 \%$ recrystallization (s); $t^{\prime \prime}$, time elapsed after $99 \%$ recrystallization (s); $t_{0.99}$, time for $99 \%$ recrystallization (s).

structures we imply the occurrence of recrystallized grains in at least $95 \%$ of the specimen volumen; similarly, calculated recrystallized volumen fractions smaller than $0.05(5 \%)$ are neglected. Another point that may need clarification is the calculation of grain sizes in partially recrystallized structures; in such cases, we have defined the average grain size (as given in all Tables and Figures in the present paper) as the volume fractionweighted grain size.

The calculated average grain sizes of austenite during the deformation schedules described in Tables 1 and 2 are shown in Figs. 4(a) to 4(f), together with the corresponding experimental values. In all cases, only events of static recrystallization and grain growth are involved in the calculations. The $\mathrm{N}$-model actually predicts that the applied deformation (0.2) surpasses the value of the critical deformation required to initiate dynamic recrystallization at 1473 and $1423 \mathrm{~K}$; nevertheless, the volumen fractions of dynamically recrystallized material predicted by this model were smaller than 0.05 and, as explained before, were neglected. Comparison between calculated and experimental values of the grain size leads to the following observations:

\subsubsection{First Deformation Step}

The grain size predicted by the three different models one second after rolling in the first deformation step (corresponding to the deformation of material with the structure of the reheated, continuously cast billet) agrees very well with the value observed at $1473 \mathrm{~K}(e . g$., see Fig. 4(a)). However, with increasing holding time the values predicted by the $\mathrm{N}$-model become considerably larger than the experimental ones, while those calculated by means of the S-model show the opposite trend. Only the grain size values predicted by the I-model remain quite close to the experimental values for holding times up to $300 \mathrm{~s}$. The overall agreement of each of the models with the experimental results is more clearly visualized by plotting the difference between predicted and observed values of the grain size, as shown in Fig. 5(a). 

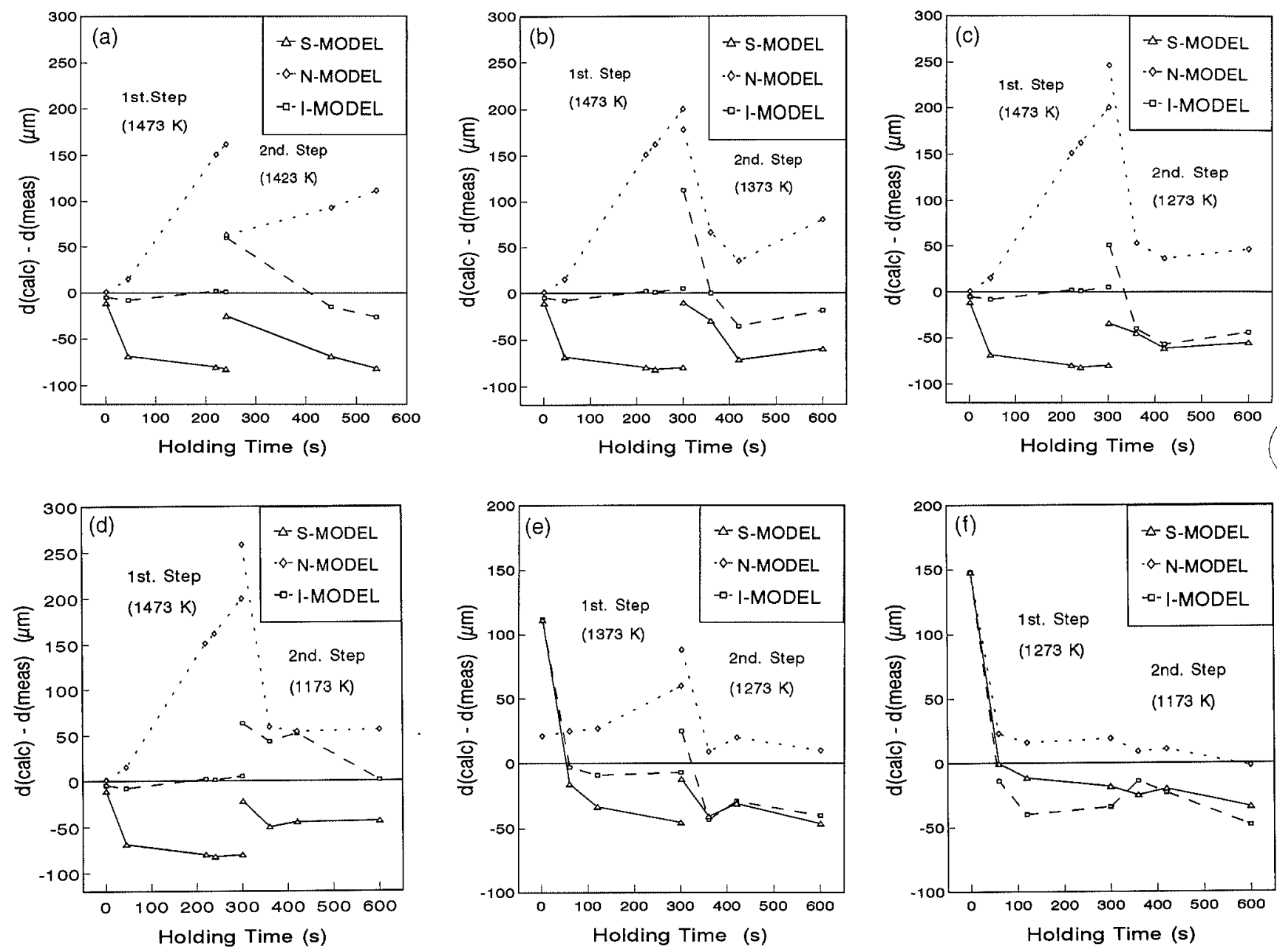

Fig. 5. (a) to (f) Difference between predicted and observed values of grain size for sequences $A-B, A-C, A-D$, A-E, C-D and A-E, respectively.

In the case of the first deformation step at $1373 \mathrm{~K}$ (Fig. 4(e)), the grain sizes predicted by the I-model again agree very well with the experimental results, except at the shortest holding time of $1 \mathrm{~s}$ (Fig. 5(e)). This is mainly due to the prediction - by all three models - of recrystallization kinetics that are slower than the actual kinetics occurring in the deformed specimens; as a consequence, the agreement between predictions and experimental values is improved at a holding time of 60 s since, by then, all the models already predict the attainment of complete recrystallization (and some grain growth). However, the $\mathrm{S}$ - and $\mathrm{N}$-models give grain size values that considerably overestimate and underestimate, respectively, the observed grain sizes over the range of holding times indicated in Figs. 4(e) and 5(e).

In the deformation schedule D-E (Fig. 4(f)), in which the first deformation step was carried out at $1173 \mathrm{~K}$, we also observe a large discrepancy between predicted and measured grain sizes at a holding time of $1 \mathrm{~s}$ (Fig. 5(f)), attributed as before to recrystallization kinetics during the experiments which are faster than those predicted by the three models. With longer holding times, in this case it is the $\mathrm{N}$ - and S-models which give the best agreement with the experimental results, while the I-model significantly underestimates the actual grain sizes.

In general, during the first deformation step we observe that the I-model predicted grain size values which were very close to the measured values at the higher temperatures (1373 and 1473 K), but became slightly inaccurate as the temperature diminished down to $1273 \mathrm{~K}$. For this model the errors at lower temperatures seem to stem mainly from inaccuracies in the predicted recrystallized grain sizes, whereas the grain growth predictions seem to hold quite well (Fig. 4(f)). On the other hand, the predictions of the $\mathrm{N}$-model improved considerably as the temperature decreased down to $1273 \mathrm{~K}$, due primarily to more accurate (slower) grain growth estimates (Figs. 4(a), 4(e) and 4(f)). Also, the grain size estimates obtained from the S-model progressively became more accurate as the temperature decreased; in this case the main factor affecting the accuracy of the predictions at high temperatures is traced back to the prediction of too slow grain growth kinetics (Figs. 4(a) to 4(f) and 5(a) to 5(c)).

\subsubsection{Second Deformation Step}

At the initiation of this step the structure in the specimens was that of a recrystallized austenite and not anymore the one from the reheated billet. It is more convenient now to describe separately the results pertaining to each of the models. It should be noticed that the calculations for each of the schedules of Table 1 (the results of which are given in Figs. 4(a) to 4(f) and 5(a) to $5(\mathrm{f}))$ were performed by taking the calculated grain 
size at the end of the first deformation step as the initial grain size for the second deformation step. Obviously, in this way any differences between calculated and measured grain sizes in the first step can influence the results for the second step.

S-Model: This model consistently underestimated the grain size values in all the deformation sequences (Figs. 4(a) to 4(f) and 5(a) to 5(f)). At temperatures of $1273 \mathrm{~K}$ and higher, the predicted recrystallized grain sizes were 40 to $80 \mu \mathrm{m}$ smaller than the experimental values, the difference usually increasing with longer holding times. Again, this points to an underestimation of the rate of grain growth by this model. In comparison, the predictions of grain size at $1173 \mathrm{~K}$ were closer to the observed values (Figs. 4(d), 4(f) and 5(d), 5(f)). But since the maximum holding time allowed at this lower temperature was barely enough for the model to predict the occurrence of complete recrystallization, the overall improvement in the agreement between calculated and measured grain sizes was mostly coincidental.

I-Model: With only one exception (Fig. 5(d)), the grain sizes calculated by means of this model showed some tendency to underestimate the measured values, especially as the holding time increased (Figs. 5(a) to 5(f)). In schedules A-B and A-C (second step at 1423 and $1373 \mathrm{~K}$, respectively), the recrystallized grain size is apparently overestimated by $30-60 \mu \mathrm{m}$ (Figs. 4(a), $4(\mathrm{~b})$ ), but since the rate of grain growth seems to have been underestimated to some degree, a sort of error compensation is observed particularly at intermediate holding times. At $1273 \mathrm{~K}$ (schedules A-D and C-D), the calculated recrystallized grain size is significantly underestimated, whereas the rate of grain growth appears to be quite similar to the one actually observed in the steel specimens (Figs. 4(c) and 4(e)). Finally, at $1173 \mathrm{~K}$ (schedules $\mathrm{A}-\mathrm{E}$ and $\mathrm{D}-\mathrm{E}$ ) considerably faster recrystallization kinetics are observed experimentally than the ones predicted by the model (Figs. 4(d), 4(f)). This leads to a situation in which, when the recrystallized grain size is $\sim 100 \mu \mathrm{m}$ (Fig. $4(\mathrm{~d})$ ), and the observed rate of grain growth is rather low, the model calculations "catch up" with the experimental values at $300 \mathrm{~s}$, but for the wrong reasons. This does not occur when the recrystallized grain size is somewhat smaller $(\sim 75 \mu \mathrm{m})$, since this seemingly provokes a significant amount of growth soon after recrystallization (Fig. 4(f)), and the differences between calculated and measured grain sizes become larger $(\sim 50 \mu \mathrm{m})$. Overall, the calculations with this model give the best estimates for sequences $\mathrm{A}-\mathrm{B}$ and $\mathrm{A}-\mathrm{C}$.

N-Model: The grain sizes calculated by this model are overestimated in practically all sequences, more noticeably in those carried out at the higher temperatures. However, with the exception of schedules A-B and $\mathrm{A}-\mathrm{C}$, other schedules show an improvement between calculated and measured grain sizes as the holding time increases and the temperature decreases (Figs. 5(a) to $5(\mathrm{f})$ ). This improvement is apparently caused by estimates of the recrystallized grain size which turn out to be increasingly closer to the measured values, while the extent of predicted grain growth is relatively small in most cases, as it is also observed experimentally.

\section{Discussion}

\subsection{Recrystallized Grain Sizes}

As indicated in a previous section, the observed microstructures point to the occurrence of static recrystallization directly from the material deformed at high temperatures; hence, dynamic recrystallization is of no consequence to the present discussion. The steel used in our work seemed to develop recrystallized grains of austenite with a size which was little influenced by temperature, in the range of 1173 to $1473 \mathrm{~K}$ or by the initial grain size, in the range 155 to $270 \mu \mathrm{m}$, as long as the deformation was held constant ( 0.2 true strain). Table 4 indicates that the maximum difference between the recrystallized grain sizes observed over this wide temperature range, under the conditions of constant strain, was apparently of only $\sim 20-25 \mu \mathrm{m}$. About the same difference is observed by changing the initial grain size from 155 to $270 \mu \mathrm{m}$, at a given temperature. This behavior is observed in both the reheated as-cast material (1st deformation step) and in the material already subjected to a previous deformation-recrystallization event (2nd deformation step).

Although not originally intended for our purposes, the effect of the amount of deformation on the recrystallized grain size of austenite was briefly surveyed by applying different rolling strains to as-cast specimens reheated to $1533 \mathrm{~K}$ and deformed at 1473 or $1373 \mathrm{~K}$. The results are summarized in Table 4 and indicate that, compared to the effect of varying the temperature or the initial grain size, the recrystallized grain size has a more marked dependence on the amount of deformation.

It might be argued that the recrystallized grain sizes quoted above were not truly those obtained right after recrystallization had occurred, but actually after some grain growth had set in. Therefore, the "true" recrystallized grain sizes would be expected to be equal or smaller than the minimum values experimentally observed.

Among the analytical expressions put forward to calculate recrystallized grain sizes included in the S-, I- and N-models, ${ }^{1,3,10,13)}$ and listed in Table 3, only the one from the I-model contains a temperature-dependent term. This equations would predict a decrease in grain size by a factor of $\sim 0.6$ for a change in temperature from $1473 \mathrm{~K}$ down to $1173 \mathrm{~K}$; clearly, a change of such magnitude was not apparent in the present study (see

Table 4. Smallest (recrystallized) grain size observed.

\begin{tabular}{cc}
\hline $\begin{array}{c}\text { Recrystallized grain size } \\
\text { in the range } 1173-1473 \mathrm{~K}\end{array}$ & $\begin{array}{r}107-127 \mu \mathrm{m}\left(d_{i}=270 \mu \mathrm{m}\right) \\
85-110 \mu \mathrm{m}\left(d_{i}=205 \mu \mathrm{m}\right)\end{array}$ \\
\hline $\begin{array}{c}\text { Recrystallized grain size } \\
\text { at } 1373 \mathrm{~K}\left(d_{i}=270 \mu \mathrm{m}\right)\end{array}$ & $\sim 150 \mu \mathrm{m}(0.1$ strain $)$ \\
& $\sim 123 \mu \mathrm{m}(0.2$ strain $)$ \\
\hline $\begin{array}{c}\text { Recrystallized grain size } \\
\text { at } 1473 \mathrm{~K}\left(d_{i}=270 \mu \mathrm{m}\right)\end{array}$ & $\sim 127 \mu \mathrm{m}(0.2$ strain $)$ \\
\hline
\end{tabular}


Table 4). On the other hand, all three models include in their respective equations terms which depend on the strain and the initial grain size; there is a good agreement between the present experimental results and the fractional changes in recrystallized grain size predicted by (i) the strain-dependent term in the I- and N-models, and (ii) the initial grain size-dependent term in the I-model. The calculated and (apparently) observed recrystallized grain sizes in the first deformation step at $1473 \mathrm{~K}$ agree very well irrespective of the model used to perform the calculations (Fig. 4(a)). At $1373 \mathrm{~K}$ (Fig. $4(\mathrm{e})$ ), the three models predict values somewhat lower than the minimum grain sizes observed experimentally, the difference being larger $(\sim 40 \mu \mathrm{m})$ by using the I-model. At $1273 \mathrm{~K}$ (Fig. 4(f)), there is again good agreement with the predictions of the $\mathrm{S}$ - and $\mathrm{N}$-models, and an underestimate of $\sim 30 \mu \mathrm{m}$ by the I-model. Consideration of the results of these comparisons as well as the metallographic evidence (Figs. 3(a)-3(1)), indicates that the smallest grain sizes observed at 1473 and $1273 \mathrm{~K}$, during the first deformation steps, were probably quite close to the true recrystallized grain sizes; in addition, the grain size observed at $1373 \mathrm{~K}$ was probably affected by grain growth after recrystallization. Therefore, the analysis of the data indeed points to a negligible effect of temperature on the recrystallized grain sizes during the first deformation step. A meaningful comparison between calculated and observed recrystallized grain sizes during the second deformation steps can only be made in those cases in which the grain sizes calculated at the end of the first deformation step coincide well with the experimental observations. In the case of the I-model, this can be done for all deformation sequences except D-E (see Figs. 4(a) to 4(f)); on the contrary, for the $\mathrm{S}$ - and $\mathrm{N}$-models a comparison may be warranted perhaps only in the latter sequence.

The recrystallized grain sizes predicted by the I-model at 1423 and $1373 \mathrm{~K}$ (2nd step) coincide quite well with the smallest experimental values (Figs. 4(a), 4(b)). At $1273 \mathrm{~K}$ (Figs. 4(c), 4(e)), the agreement is much less satisfactory, but it might be conceivable that this happens as a result of the observation of grain sizes already affected by grain growth. However, at $1173 \mathrm{~K}$ (Fig. $4(\mathrm{~d})$ ), there is a definite underestimation of the recrystallized grain size by I-model. In turn, the smallest grain size observed at $1173 \mathrm{~K}$ in sequence D-E (Fig. 4(f)) is very close to the recrystallized grain size predicted by the $\mathrm{N}$-model, but considerably larger than one predicted by the S-model, although in the latter case, about half of the difference may be "inherited" from the previous deformation step.

Overall, the previous comparisons, although certainly limited in number, seem to indicate that all three models predicted recrystallized grain sizes quite well in the interval 1 373-1 $473 \mathrm{~K}$. At lower temperatures, we can only say that the I-model showed an increasing tendency to underestimate the "observed" recrystallized grain sizes as the temperature decreased down to $1173 \mathrm{~K}$.

\subsection{Grain Growth}

The pertinent results are grouped together in Table 5.
Table 5. "Final" grain sizes observed after recrystallization and grain growth.

\begin{tabular}{ccc}
\hline Temperature $(\mathrm{K})$ & Strain & Observed grain sizes $(\mu \mathrm{m})^{*}$ \\
\hline 1473 & 0.2 & 205 \\
1473 & 0.34 & 196 \\
1473 & 0.41 & 200 \\
1423 & 0.2 & 191 \\
1373 & 0.2 & 155,157 \\
1373 & 0.1 & 200 \\
1273 & 0.2 & $120,125,130$ \\
1173 & 0.2 & 91,107 \\
\hline
\end{tabular}

* When two or three values are listed, each of them corresponds to different initial grain sizes $\left(d_{i}\right.$ in Table 2$)$.

The most important observation from the experimental results in the present work is the clear dependency of the "stable" (final) grain size (after recrystallization) on the holding temperature alone (for a fixed strain). In this respect, the austenite grain size immediately before the deformation by rolling seemingly had no effect at all, expect perhaps at the lowest temperature $(1173 \mathrm{~K})$; however, in this last case it is not certain whether the longest holding time used in our experiments was enough to establish a "stable" grain size by growth (see Figs. 4(d), 4(f)) and, therefore, those results do not necessarily contradict the general tendencies in the results of Table 5. It is noted that the application of strains in the range $0.2-0.4$ at a temperature of $1473 \mathrm{~K}$ did not materially affect the value of the final grain size either; in contrast, a specimen deformed by the amount of 0.1 strain at $1373 \mathrm{~K}$ showed a final grain size $(200 \mu \mathrm{m})$ significantly larger than the one obtained with a strain of 0.2 (155$157 \mu \mathrm{m})$. Our experiments did not include a sufficient number of tests with varying amounts of strain to permit at this point further discussion on the effect of strain.

It may be relevant to notice that the recrystallization and grain growth behavior observed in specimens with as-reheated microstructures did not differ from those of specimens subjected to a previous event of static recrystallization. This fact is more clearly seen by comparing the grain size values measured during the first steps (as-reheated material) of sequences C-D and D-E (i.e., at 1373 and $1273 \mathrm{~K}$, respectively) to those obtained from the second steps (recrystallized material) of sequences A-C and A-D, respectively, as shown by Figs. 4(c) to 4(f). In both instances, grain sizes take very similar values at a given temperature, notwithstanding the fact that the initial microstructures were obtained through different processing treatments (with $v s$. without previous deformation) and actually had considerably different initial austenite grain sizes. It must be concluded then that the recrystallization and growth behavior of the microstructure of the continuously-cast steel billet used in the present experiments is not affected by segregation patterns once it has been subjected to the (typical) reheating temperature of $1533 \mathrm{~K}$.

The functional forms of the grain growth equations encountered in the three models of microstructural evolution (Table 3) do not lend itselves to being qualitatively compared with the experimental observations mentioned above. But Figs. 4(a) to 4(f) and 5(a) to 5(f) 
offer some clear tendencies to the eye. During the first deformation steps at 1273,1373 and $1473 \mathrm{~K}$ (Figs. 4(a), 4(e) and 4(f)) the rate of grain growth is accurately predicted only by the I-model, while the $\mathrm{N}$ - and S-models give considerable overestimates and underestimates, respectively, as mentioned before. During the second deformation steps, the I-model seems to provide good estimates of the rate of grain growth in the interval of 1273 to $1423 \mathrm{~K}$, but with a slight tendency to underestimate it. Since the only difference between those two sets of experimental conditions apparently resides in the initial grain sizes, it is concluded that the I-model may not account fully for the effect of this last parameter on the rate of grain growth, particularly as the initial grain size decreases.

On the other hand, the rate of grain growth predicted by the $\mathrm{N}$-model starts getting very close to the experimental observations at temperatures of $1423 \mathrm{~K}$ and lower, during the 2 nd deformation steps (Figs. 4(b) to $4(f))$. In this case, the kinetics of recrystallization predicted by the $\mathrm{N}$-model coincided reasonably well with the experimental observations (Figs. 4(d) and 4(f)). The comparison can be extended even to the lowest temperature $(1173 \mathrm{~K})$ used in the experiments. The major discrepancies in the rate of grain growth predicted by this model arise at intermediate and longer times ( $\geq 50 \mathrm{~s}$ ) at high temperatures (1373-1 473 K), while the initial rates of growth are in good agreement with observations even at those temperatures.

At last, the S-model gives reasonably good estimates of the rate of grain growth at temperatures of 1373 and $1273 \mathrm{~K}$ (2nd deformation steps); at higher temperatures, the initial rates of grain growth are grossly underestimated.

It is clear from the above that the largest differences between predicted and apparent rates of grain growth occur at high temperatures and large grain sizes when using the $\mathrm{N}$ - and S-models. The I-model, however, gave good estimates for all conditions included in the present work.

Sellars ${ }^{10}$ ) has previously compared some of the models' predictions, particularly as regards predicted grain sizes. When we consider together the results of the present work and those in Sellars' paper, ${ }^{10}$ ) it is evident that the large numerical value of the grain size exponent in the grain growth equation of Sellars (Table 3) makes a difference only for relatively small $(\leq 60-70 \mu \mathrm{m})$ initial grain sizes, but not so for the larger grain sizes found in most of our experiments.

\subsection{Overall Agreement among Models and Experiments in the Two Step Deformation Sequences}

First, it should be noticed that the above comparisons between models' predictions and experimental results might not be quite fair in all respects. Even though it has been suggested that the $\mathrm{S}-, \mathrm{N}$ - and I-models are applicable in general to C-Mn steels, ${ }^{1,3,14)}$ it is expected that they will be more accurate in predicting the behavior of the type of steels from which most of the experimental data were previously obtained, namely, low carbon steels. Nevertheless, while marked differences in the re- crystallization and grain growth behavior of austenite have been noticed between $\mathrm{C}-\mathrm{Mn}$ and microalloyed steels, ${ }^{1-4,7,9)}$ no such differences have been reported among $\mathrm{C}-\mathrm{Mn}$ steels of different compositions or even between $\mathrm{C}-\mathrm{Mn}$ steels and low alloy steels ${ }^{15}$; but it should be kept in mind that suitable data in the literature on medium and high carbon steels, as well a low-alloy steels, is very scarce.

I-Model: This model provided accurate grain size predictions during sequences $\mathrm{A}-\mathrm{B}$ and $\mathrm{A}-\mathrm{C}$, which involved the use of high temperatures (1 373-1 473 K). The agreement included both recrystallized grain sizes as well as grain growth behavior (Figs. 4(a), 4(b) and 5(a), 5(b)). The accuracy of predictions decreased somewhat as the temperatures decreased; the previous analysis has shown that this was due mainly to the underestimation of recrystallized grain sizes by the model, although an additional effect at the lower temperatures was related to the predicted recrystallization kinetics which were much slower that those observed in our experiments. In the specific circumstances of the present work, the form of the grain growth equation in the I-model (Table 3) clearly turned out to represent much more conveniently the actual behavior in the mediumcarbon steel. On the other hand, the predicted temperature dependence of the statically recrystallized grain size was overemphasized.

S-Model: At high temperatures the kinetics of grain growth predicted by this model were markedly slower than those observed experimentally, resulting in large differences between calculated and observed grain sizes at the end of the 1st deformation steps. However, these differences were considerably reduced in magnitude as the temperature decreased. In addition, the predicted recrystallization kinetics were visibly slower than the observed behavior at $1173-1273 \mathrm{~K}$; the predicted recrystallized grain size agreed reasonably well with the experiments in the 1st deformation steps, but no meaningful comparison could be made in other circumstances. In most cases, this model underestimated the observed grain sizes by about $50 \mu \mathrm{m}$, and at temperatures of 1173 and $1273 \mathrm{~K}$ the disagreement involved the prediction of too slow recrystallization kinetics. Nevertheless, the convergence of different types of "errors" as the deformation sequence proceeded (e.g., sequences C-D or D-E, Figs. 4(e), 4(f)) did not seem to produce a summation of errors; apparently, the model's equations led gradually to smaller values of recrystallized grain sizes which did not vary considerably with the initial grain size, and were not later affected much by grain growth. In other words, recrystallized grain sizes tend to be smaller, and remain so (slow grain growth) as subsequent deformation steps are applied at temperatures which decrease from one step to the other.

N-Model: The kinetics of recrystallization and the recrystallized grain sizes predicted by this model agreed fairly well with the experimental observations, particularly at temperatures of $1373 \mathrm{~K}$ and lower, at which the predicted rate of grain growth was also close to the 
observations. At higher temperatures, the predicted rate of grain growth was grossly overestimated; the dependence of the recrystallized grain size on the initial grain size in the corresponding equation of the model (Table 3 ) is such that the "errors" in the value of the initial grain size are not fully inherited by the calculated grain size on recrystallization. Therefore, as the temperature decreased, the grain size predictions of this model had a tendency to coincide better with the experimental observations. When compared to the I- and S-models, the $\mathrm{N}$-model resulted in a much more accurate prediction of the rate of recrystallization, under the conditions of the present experiments, particularly at temperatrues of 1173 and $1273 \mathrm{~K}$.

The fact that the three models considered here can predict: i) statically recrystallized grain sizes which decrease markedly with decreasing temperature and are not strongly affected by other material or process parameters and ii) rates of grain growth which become almost nil at temperatures lower than about $1300 \mathrm{~K}$, practically ensures that their predictions will become better as the number of deformations steps increase and the temperatures progressively decrease, provided the events of recrystallization are allowed to continue to full completion between deformation steps. Further experimentation is now in preparation in order to make a critical examination of the above models under conditions leading to partial recrystallization between steps.

\section{Conclusions}

(1) Under deformation conditions which lead only to static recrystallization in a medium-carbon steel, we have found that the microstructural model of the IRSID group was able to predict austenite grain sizes with reasonable accuracy in most situations. The models proposed by the researchers at Sheffield University and Nippon Steel Corp. improved their predictions as the temperatures decreased; at high temperatures (1373$1473 \mathrm{~K}$ ) the latter models did not offer accurate predictions of the rate of grain growth for the particular steel used in the present work.

(2) Rates of recrystallization calculated by the I- and S-models did not agree quite well with those deduced from metallographic observations, particularly at temperatures in the range $1173-1373 \mathrm{~K}$. The agreement was somewhat between with the predictions given by the $\mathrm{N}$-model.

(3) It is clear that as long as the models incorporate equations yielding recrystallized grain sizes and grain growth rates which decrease markedly with decreasing temperature, the calculated grain sizes for multiple-step deformation sequences, in which the temperature is progressively lowered, will not be too far from the observed values.
(4) Conditions of deformation at high temperatures, or partial recrystallization at intermediate or lower temperatures in the austenite range, will impose more serious constraints in the details of the models' equations. But only the latter conditions may be of practical importance in industrial applications.

\section{Acknowledgments}

This work was performed under the financial support of Instituto Politécnico Nacional (project DEPI 913171) as well as the partial support of CONACYT (grant P226CCON882381) and the Organization of American States (PRDCYT 90-91). J.J.C.R. was a recipient of CONACYT and PIFI-IPN scholarships, and thanks Instituto de Metalurgia for provision of facilities for the realization of this work. J.G.C.M. acknowledges a COFFA-IPN fellowship.

\section{REFERENCES}

1) C. M. Sellars: Hot Working and Forming Process, ed. by C. M. Sellars and G. J. Davies, Institute of Metals, London, (1980), 3.

2) C. M. Sellars: Annealing Processes-Recovery, Recrystallization and Grain Growth, Proc. of 7th Risø Int. Symp., ed. by N. Hansen et al., Risø Nat'l. Laboratory, Roskilde, Denmark, (1986), 167.

3) P. Choquet, A. LeBon and Ch. Pedrix: Proc. 7th Int. Conf. on Strength of Metals and Alloys, ed. by H. J. McQueen et al., Pergamon Press, Toronto, (1985), 1025.

4) P. Choquet, P. Fabreque, J. Guisti, B. Chamont, J. N. Pezant and F. Blanchet: Proc. Int. Symp. on Mathematical Modelling of Hot Rolling of Steels, ed. by S. Yue and A. F. Crawley, The Canadian Institute of Metallurgists, Hamilton, Canada, (1990), 1 .

5) T. Suehiro, K. Sato, H. Yada, T. Senuma and Y. Matsumura: Trans. Iron Steel Inst. Jpn., 27 (1987), 439.

6) H. Yada: Accelerated Cooling of Rolled Steel, ed. by G. E Ruddle and A. F. Crawley, Pergamon Press, New York, (1988), 105

7) E. Anelli, M. Ghersi, A. Mascanzoni, M. Paolicchi, A. Aprile, F. Granato, G. Liguori and G. Rizzo: HSLA Steels: Metallurgy and Applications, ed. by J. M. Gray et al., ASM, Metals Park, $\mathrm{OH},(1986), 693$.

8) P. D. Hogdson and R. K. Gibbs: ISIJ Int., 32 (1992), 1329.

9) e.g., Recent Advances in Modelling of Microstructural Evolution and Properties of Steels, ISIJ Int., 32 (1992), No. 3 (special issue).

10) C. M. Sellars: Proc. Int. Symp. on Mathematical Modelling of Hot Rolling of Steels, ed. by S. Yue and A. F. Crawley, The Canadian Institute of Metallurgists, Hamilton, Canada, (1990), 1 .

11) R. Martínez-Sánchez and J. G. Cabañas-Moreno: Mater. Sci. Forum, 113-115 (1992), 503.

12) J. J. Cruz Rivera: M. S. Thesis, ESIQIE-Instituto Politécnico Nacional, México, D. F., (1993)

13) T. Senuma, H. Yada, Y. Matsumura and T. Futamura: Tetsu-toHagané, 70 (1984), 2112.

14) T. Senuma and Y. Yada: Annealing Processes-Recovery, Recrystallization and Grain Growth, Proc. 7th Risø Int. Symp., ed. by N. Hansen et al., Risø Nat'l. Laboratory, Roskilde, Denmark, (1986), 547.

15) E. Ruibal, J. J. Urcola and M. Fuentes: Mater. Sci. Technol., 1 (1985), 732. 